\title{
3D characterization of partially recrystallized Al using high resolution diffraction contrast tomography
}

Sun, Jun; Yu, Tianbo; Xu, Chaoling; Ludwig, Wolfgang; Zhang, Yubin

Published in:

Scripta Materialia

Link to article, DOI:

10.1016/j.scriptamat.2018.08.001

Publication date:

2018

Document Version

Peer reviewed version

Link back to DTU Orbit

Citation (APA):

Sun, J., Yu, T., Xu, C., Ludwig, W., \& Zhang, Y. (2018). 3D characterization of partially recrystallized Al using high resolution diffraction contrast tomography. Scripta Materialia, 157, 72-75.

https://doi.org/10.1016/j.scriptamat.2018.08.001

\section{General rights}

Copyright and moral rights for the publications made accessible in the public portal are retained by the authors and/or other copyright owners and it is a condition of accessing publications that users recognise and abide by the legal requirements associated with these rights.

- Users may download and print one copy of any publication from the public portal for the purpose of private study or research.

- You may not further distribute the material or use it for any profit-making activity or commercial gain

- You may freely distribute the URL identifying the publication in the public portal 
Materialia

Manuscript Number: SMM-18-1215R1

Title: 3D characterization of partially recrystallized Al using high resolution diffraction contrast tomography

Article Type: Regular article

Keywords: recrystallization; 3D reconstruction; Schwartz-Saltykov analysis; electron backscattering diffraction (EBSD); aluminium

Corresponding Author: Dr. Yubin Zhang, Ph.D

Corresponding Author's Institution: Technical University of Denmark

First Author: Jun Sun

Order of Authors: Jun Sun; Tianbo Yu; Chaoling Xu; Wolfgang Ludwig; Yubin Zhang, Ph.D

Abstract: Synchrotron diffraction contrast tomography (DCT) is for the first time used to characterize recrystallized grains in partially recrystallized Al. The positions, orientations and 3D shapes of more than 900 recrystallized grains are reconstructed within a gauge volume. The results are compared with those obtained using electron backscattered diffraction based on a statistical analysis. It is found that recrystallized grains with size larger than $10 \mu \mathrm{m}$, corresponding to $\sim 98 \%$ of the total recrystallized volume of the sample, are well characterized by DCT. The advantages of DCT for recrystallization studies and new possibilities with DCT on new generation synchrotron sources are discussed. 


\title{
3D characterization of partially recrystallized Al using high resolution diffraction contrast tomography
}

Jun Sun ${ }^{1,2}$, Tianbo Yu ${ }^{1}$, Chaoling Xu ${ }^{3}$, Wolfgang Ludwig ${ }^{4,5}$, Yubin Zhang ${ }^{1 *}$

${ }^{1}$ Department of Mechanical Engineering, Technical University of Denmark, 2800 Kgs. Lyngby, Denmark.

${ }^{2}$ Xnovo Technology, 4600 Køge, Denmark

${ }^{3}$ Department of Management and Engineering, Linköping University, SE-58183

Linkoping, Sweden

${ }^{4}$ ESRF, 6 rue Jules Horowitz, Grenoble 38043, France.

${ }^{5}$ University of Lyon, MATEIS, INSA-Lyon, UMR 5510 CNRS, 7 Avenue Jean Capelle, Villeurbanne 69621, France.

*Email address: yubz@mek.dtu.dk; postal address: Technical University of Denmark, Produktionstorvet, Building 425, room 214, 2800 Kgs. Lyngby, Denmark. Phone: +45 45254752.

\begin{abstract}
:
Synchrotron diffraction contrast tomography (DCT) is for the first time used to characterize recrystallized grains in partially recrystallized Al. The positions, orientations and 3D shapes of more than 900 recrystallized grains are reconstructed within a gauge volume. The results are compared with those obtained using electron backscattered diffraction based on a statistical analysis. It is found that recrystallized grains with size larger than $10 \mu \mu \mathrm{m}$, corresponding to $\sim 98 \%$ of the total recrystallized volume of the sample, are well characterized by DCT. The advantages of DCT for recrystallization studies and new possibilities with DCT on new generation synchrotron sources are discussed.
\end{abstract}


Keywords: recrystallization; 3D reconstruction; Schwartz-Saltykov analysis; electron backscattering diffraction (EBSD); aluminium

During recrystallization of deformed materials, nearly defect-free nuclei/grains form and grow at the expense of the surrounding deformed matrix. Recent $3 \mathrm{D}$ results obtained using serial sectioning have shown that the distribution of nuclei/recrystallized grains is heterogeneousnon-uniform, and depends strongly on the local deformation microstructure [1-4]. Although both deformed matrix and nuclei/recrystallized grains can be characterized with these techniques, only limited volume or limited spatial resolution can be obtained when the sectioning is done with focused ifon beam [1] or mechanical polishing [2-4], respectively. More importantly, the destructive nature of the techniques prohibits the possibility of dynamic studies to follow the recrystallization process, which is essential for a better understanding of the heterogeneities of recrystallization.

During the last 15-20 years, several non-destructive 3D characterization techniques have been invented and implemented using synchrotron X-rays, including 3D X-ray diffraction (3DXRD) [5-8], diffraction contrast tomography (DCT) [9,10], Bragg coherent diffraction imaging [11,12] and 3D X-ray Laue microdiffraction $[13,14]$. Among these techniques, DCT allows fast 3D reconstruction of grains in fully recrystallized samples $[15,16]$. Although the nuclei/grains in partially recrystallized samples are also in the recrystallized state (i.e. with very low densities of interior defects), the nuclei/grains are relatively small compared to those in fully recrystallized samples. At the same time, parts of the microstructure consist of deformed grains with significant orientation variations and strain gradients. Some of the nuclei/grains may have orientations similar to the neighboring deformation grains, from which they originate. All these factors make reconstruction of the recrystallized 
grain very challenging [10]. To what extend DCT can be used to characterize partially recrystallized samples is therefore still an open question.

In the present paper, we will for the first time explore the applicability of DCT for recrystallization characterization. A partially recrystallized Al sample will be used as a model material. To validate the DCT results, they will be compared with those obtained based on conventional characterization using electron backscattered diffraction (EBSD). Statistical analysis will be performed to link the 2D EBSD and the 3D DCT results and ease the interpretation of the results.

Commercial purity aluminium, A11050, was used for the present study. The starting material had a fully recrystallized microstructure with an average grain size of $\sim 50 \mu \mu \mathrm{m}$. The material was then cold rolled to $50 \%$ reduction in thickness, followed by annealing at $325^{\circ} \mathrm{C}$ for $0.5 \mathrm{~h}$ to obtain a partially recrystallized microstructure. For the synchrotron DCT measurement, pillar samples with cross-section of $\sim 420 \times 420$ $\underline{\mu \mathrm{m}^{2}}$ were cut out using electrical discharge machining. The DCT measurement was conducted at beamline ID11 at the European Synchrotron Radiation Facility (ESRF). The X-ray energy was $37 \mathrm{keV}$. The direct X-ray beam was constrained by two sets of vertical and horizontal slits to $240 \times 420 \mu \mathrm{m}^{2}$. Transfocators with beryllium lenses were used to focus the beam. A uniform beam was obtained within the defined gauge. The sample was mounted on an $\omega$ rotation stage with the sample rolling direction (RD) parallel to the vertical rotation axis. A full $360^{\circ}$ scan was performed with angular integration steps of $0.1^{\circ}$ and an exposure time of $2 \mathrm{~s}$. Both the diffracted and the transmitted beam were recorded using a near-field detector (comprising a transparent luminescent screen, light optically coupled to a CCD) with $2048 \times 2048$ pixels positioned normal to the incident beam at a sample-to-detector distance of 3 $\mathrm{mm}$. To improve the spatial resolution, an eyepiece was used to magnify the 
diffraction images. The effective pixel size of the detector system was $0.77 \mu \mu \mathrm{m}$. The detailed information about the DCT setup can be found in $[9,10]$.

A typical diffraction image is shown in Fig. 1. Most of the diffraction spots, e.g. those marked by the red arrows, are sharp and well-defined, appearing typically at 1-2 consecutive angular steps. These diffraction spots originate from recrystallized grains. Only few blurry, large and weak diffraction spots, as the one marked by the yellow ellipse, are visible and appear typically over a large number of angular steps. These originate from the deformed matrix.

The diffraction images were analyzed with the DCT software (http://sourceforge.net/projects/dct) available at the beamline. A recently developed algorithm allowing $6 \mathrm{D}$ reconstruction (3D for position $+3 \mathrm{D}$ for orientation) $[17,18]$ is used to reconstruct the grain shapes. In total 929 recrystallized grains are found within the gauge volume. The 3D volume is shown in Fig. 2a. The recrystallized grains are typically not spherical but elongated along the RD and the transverse direction (TD). Also the recrystallized grains are not randomly distributed, but clustered $\underline{\text { in bands }}$ parallel to the RD and TD. For clear visualization, a typical 2D section is shown in Fig. 2b. The volume fraction, $V_{\mathrm{V}}$, of the recrystallized grains is about $24 \%$ and the average grain size (defined as equivalent spherical diameter (ESD)) is about $18 \underline{\mu} \mu \mathrm{m}$.

The number of grains per unit volume, $N_{\mathrm{V}}$, (determined by $N_{\text {total }} / V$, where $V$ is the gauge volume) is about $2.7 \times 10^{-5} \underline{\mu} \mu \mathrm{m}^{-3}$ (see Table 1 ).

Table 1. Microstructural parameters for recrystallized grains calculated based

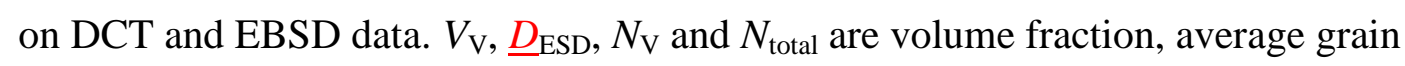
size, number of grains per unit volume and total grain number, respectively. For EBSD data, the $\underline{D S D}_{\mathrm{ES}} E S$ was calculated based on the statistical analysis. 


\begin{tabular}{|c|c|c|c|c|}
\hline & $V_{\mathrm{v}}$ & $\begin{array}{l}\underline{\mathrm{ESD}}^{\mathrm{ES}} \\
(\underline{\mu} \mu \mathrm{m})\end{array}$ & $N_{\mathrm{V}}\left(10^{-5} \underline{\mu} \mu \mathrm{m}^{-3}\right)$ & $N_{\text {total }}$ \\
\hline DCT & $24 \%$ & 18.4 & 2.7 & 929 \\
\hline EBSD & $28 \pm 4 \%$ & 14.6 & 4.1 & 469 \\
\hline
\end{tabular}

To verify the $3 \mathrm{D}$ results, the microstructure of the sample was characterized using a Zeiss Supra 35 field emission gun scanning electron microscope equipped with a Channel 5 EBSD system. EBSD measurements were conducted on the longitudinal section (defined by the RD and normal direction (ND)) using a scanning step size of $0.5 \underline{\mu} \mu \mathrm{m}$, covering two areas of $\sim 6.7 \times 10^{5} \underline{\mu} \mu \mathrm{m}^{2}$.

An example of the EBSD maps is shown in Fig. 3a. The recrystallized grains are selected from the EBSD maps using the following criteria: i) grain size (equivalent circular diameter, ECD), larger than $3 \mu \mu \mathrm{m}$, ii) surrounded at least partly by high angle boundaries to the deformed matrix, iii) the internal misorientation angle is less than $1^{\circ}$. Fig. $3 \mathrm{~b}$ shows the recrystallized grains only. Similar to the $3 \mathrm{D}$ results, clusters of recrystallized grains are seen in bands parallel to the RD. In total, 469 recrystallized grains are found. The $V_{\mathrm{V}}$ determined based on EBSD maps is slightly higher than that of the $3 \mathrm{D}$ result.

It should be noted that on the EBSD maps not all grains are sectioned through their maximum diameter; many grains appear smaller than they actually are, and large grains have a higher chance to be sectioned than small grains. A statistical analysis using stereology is required to link the 2D EBSD and 3D DCT data. In the present paper, the Schwartz-Saltykov (SS) method, which is a standard way to calculate 3D grain size $\left(\underline{D}_{\mathrm{ESD}}\right)$ distribution based on the 2D size ( $\left.\underline{D}_{\mathrm{ECD}}\right)$ distribution [19], is 
performed to calculate the $N_{\mathrm{V}}$ and the average grain size (see the supplementary materials).

The results show that the $N_{\mathrm{V}}$ determined from SS analysis is $\sim 30 \%$ higher than that from DCT data (see Table 1). In other words, $\sim 30 \%$ of the recrystallized grains are not seen in the DCT data set. To further understand the missing grains, the distributions of $N_{\mathrm{V}}$ calculated from DCT and EBSD data are compared (see Fig. 4). It is evident that the two distributions agree well to each other for the size range larger than $10 \underline{\mu} \mu \mathrm{m}$, whereas DCT significantly underestimated the fraction of the small grains $(<10 \underline{\mu} \mu \mathrm{m})$. This comparison suggests that the low $N_{\mathrm{V}}$ of the DCT data is primarily attributed to the small grains, which have been poorly indexed by DCT. As a result, the average grain size determined based on the DCT data is larger than that from the SS analysis, while the volume fraction of the recrystallized grains measured from DCT data is slightly smaller than that from EBSD data (see Table 1).

The reason for the poor indexing of the small recrystallized grains is that the small grains (especially in volumes) produce weak diffraction spots, which are difficult to distinguish from the background noise and the diffused diffraction signal from deformation matrix. As the intensities of diffraction spots from hkl families with high numbers are much weaker than those with low numbers, identification of high numbered hkl diffraction spots for even medium size grains (in the range 7-10 $\mu \mu \mathrm{m}$ ) is a challenge. As a result, only a limited number of diffraction spots from low numbered hkl families can be segmented properly, which is insufficient for indexing and reconstructing the grains.

Despite the large number of the small recrystallized grains which are not indexed by DCT, the volume fraction of those small grains is only less than $2 \%$ of the total volume fraction of the recrystallized grains (see-in Fig. 4). As recrystallization 
proceeds and the nuclei/grains grow to large sizes and thus can be properly reconstructed, this situation can be further remedied.

Compared with other 3D characterization techniques, such as 3DXRD [20-23] and X-ray Laue microdiffraction [24,25], DCT has several advantages for recrystallization studies. i) A large number of grains can be characterized simultaneously, allowing a statistically-sound analysis, e.g. the 3D recrystallization kinetics. ii) DCT provides fast measurements of reasonably large volumes (e.g. $\left.400 \times 400 \times 300 \mu \mu \mathrm{m}^{3}\right)$. A typical DCT scan takes about $2 \mathrm{~h}$. With the upcoming synchrotron upgrade, the X-ray intensity can be improved by a factor of 40-100 [26]. With that implemented, both the spatial resolution (in term of the minimum detectable grain size) and the temporal resolution can be improved significantly. In combination with in-situ annealing, dynamic studies of recrystallization studies-can be performed in the near future.

\section{Acknowledgements:}

YBZ thanks Prof. D. Juul Jensen for the useful comments during the preparation of the manuscript.

\section{References:}

[1] W. Xu, M.Z. Quadir, M. Ferry, Metall. Mater. Trans. A Phys. Metall. Mater. Sci. 40 (2009) 1547-1556.

[2] G.H. Fan, Y.B. Zhang, J.H. Driver, D. Juul Jensen, Scr. Mater. 72-73 (2014) 9-12.

[3] Y. Zhang, D. Juul Jensen, Y. Zhang, F. Lin, Z. Zhang, Q. Liu, Scr. Mater. 67 (2012) 320-323.

[4] Z. Sükösd, K. Hannesson, G. Wu, D. Juul Jensen, 3rd Int. Conf. Recryst. Grain 
Growth, ReX GG III 558-559 (2007) 345-350.

[5] H.F. Poulsen, W. Ludwig, E.M. Lauridsen, S. Schmidt, W. Pantleon, U. Olsen, J. Oddershede, P. Reischig, A. Lyckegaard, J. Wright, G. Vaughan, in:, 31st Risø Int. Symp. Mater. Sci., 2011, pp. 101-119.

[6] H.F. Poulsen, J. Appl. Crystallogr. 45 (2012) 1084-1097.

[7] D. Juul Jensen, H.F. Poulsen, Mater. Charact. 72 (2012) 1-7.

[8] S. Schmidt, S.F. Nielsen, C. Gundlach, L. Margulies, X. Huang, D. Juul Jensen, Science 305 (2004) 229-32.

[9] W. Ludwig, P. Reischig, A King, M. Herbig, E.M. Lauridsen, G. Johnson, T.J. Marrow, J.Y. Buffière, Rev. Sci. Instrum. 80 (2009) 033905.

[10] P. Reischig, A. King, L. Nervo, N. Viganó, Y. Guilhem, W.J. Palenstijn, K.J. Batenburg, M. Preuss, W. Ludwig, J. Appl. Crystallogr. 46 (2013) 297-311.

[11] T.W. Cornelius, O. Thomas, Prog. Mater. Sci. 94 (2018) 384-434.

[12] A. Yau, W. Cha, M. Kanan, G.B. Stephenson, A. Ulvestad, Science 356 (2017) 739-742.

[13] B. Larson, W. Yang, G. Ice, J. Budai, J. Tischler, Nature 415 (2002) 887-890.

[14] B.C. Larson, L.E. Levine, J. Appl. Crystallogr. 46 (2013) 153-164.

[15] A. King, G. Johnson, D. Engelberg, W. Ludwig, J. Marrow, Science 321 (2008) 382-385.

[16] J. Zhang, Y. Zhang, W. Ludwig, D. Rowenhorst, P.W. Voohees, H.F. Poulsen, Acta Mater. Accepted.

[17] N. Viganò, W. Ludwig, K.J. Batenburg, J. Appl. Crystallogr. 47 (2014) 18261840.

[18] N. Viganò, A. Tanguy, S. Hallais, A. Dimanov, M. Bornert, K.J. Batenburg, W. Ludwig, Sci. Rep. (2016) 20618. 
[19] E.E. Underwood, Quantitative Stereology., Addison-Wesley, 1970.

[20] F.X. Lin, Y.B. Zhang, W. Pantleon, D. Juul Jensen, Philos. Mag. 95 (2015) $2427-2449$.

[21] S. Storm, D. Juul Jensen, Scr. Mater. 60 (2009) 477-480.

[22] S.S. West, S. Schmidt, H.O. Sørensen, G. Winther, H.F. Poulsen, L. Margulies, C. Gundlach, D. Juul Jensen, Scr. Mater. 61 (2009) 875-878.

[23] S. Van Boxel, S. Schmidt, W. Ludwig, Y.B. Zhang, D. Juul Jensen, W. Pantleon, Mater. Trans. 55 (2014) 128-136.

[24] Y.B. Zhang, J.D. Budai, J.Z. Tischler, W. Liu, R. Xu, E.R. Homer, A. Godfrey, D. Juul Jensen, Sci. Rep. 7 (2017).

[25] C. Xu, Y. Zhang, A. Godfrey, G. Wu, W. Liu, J.Z. Tischler, Q. Liu, D. Juul Jensen, Sci. Rep. 7 (2017) 42508.

[26] ESRF upgrade programme phase II (2015-2019) white paper.

Figure captions:

Figure 1. A typical near-field diffraction image of the partially recrystallized $\mathrm{Al}$ sample, recorded using a near-field detector with $2048 \times 2048$ pixels (pixel size of 0.77 $\underline{\mu m})$. The red arrows mark examples of diffraction spots originating from recrystallized grains, while the yellow ellipse marks diffraction from a deformed grain. The rectangle region in the middle is from the direct X-ray beam. Figure 2. 3D reconstruction of recrystallized grains measured by DCT. (a) The 3D volume of $240 \times 420 \times 420 \mu \mathrm{m}^{3}$; (b) a 2D section. The colors in both (a) and (b) represent the crystallographic orientation along RD (see the inset in (ba)). In (b) thin 
and thick black lines represent boundaries with misorientation $>2^{\circ}$ and $>15^{\circ}$, respectively. The voxel/pixel size is $0.77 \mu \mathrm{m}$.

Figure 3. Example of mMicrostructure of the partially recrystallized Al sample: (a) full map, (b) recrystallized grains. The colors used in the EBSD maps correspond to the crystallographic orientations along sample RD (see the inset in (b)) direction. Thin and thick black lines represent boundaries with misorientation $>2^{\circ}$ and $>15^{\circ}$, respectively. The pixel size of the EBSD map is $0.5 \mu \mathrm{m}$. Figure 4. Distributions of grain size $\left(D_{\mathrm{ESD}}\right)$ and volume fraction Size (ESD) distribution of recrystallized grains determined based on EBSD and DCT data. The volume fraction is calculated based on the distribution of $N_{\mathrm{V}}$ from the EBSD data using SS method. 


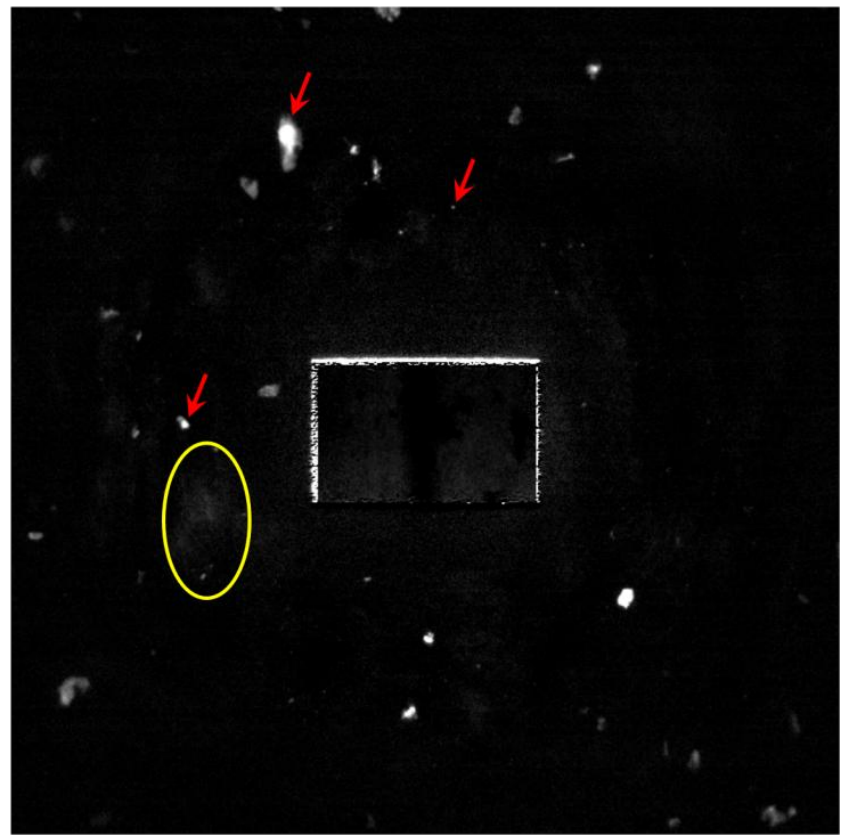

Figure 1. A typical near-field diffraction image of the partially recrystallized $\mathrm{Al}$ sample, recorded using a near-field detector with $2048 \times 2048$ pixels (pixel size of $0.77 \mu \mathrm{m}$ ). The red arrows mark examples of diffraction spots originating from recrystallized grains, while the yellow ellipse marks diffraction from a deformed grain. The rectangle region in the middle is from the direct X-ray beam. 

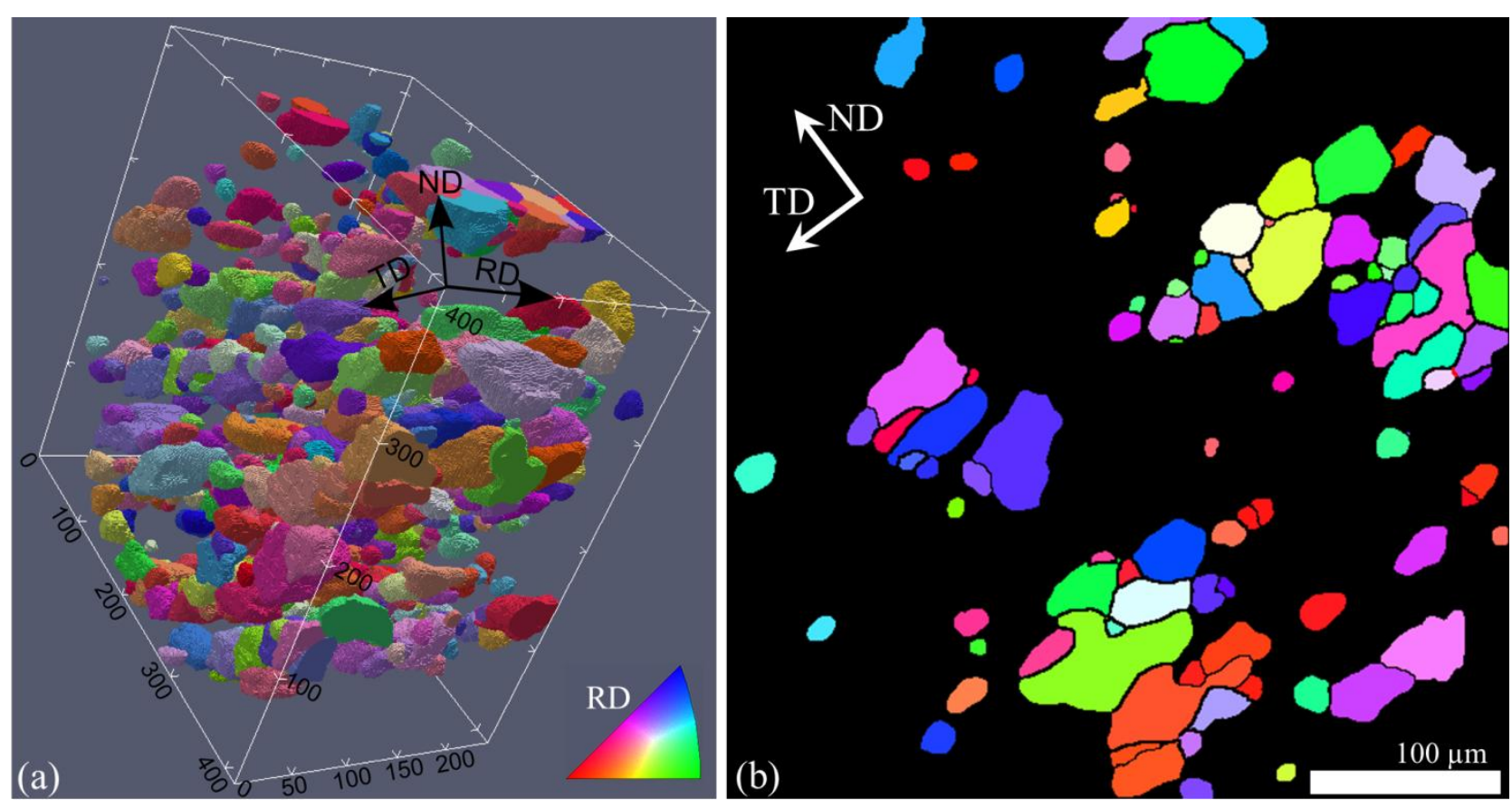

Figure 2. 3D reconstruction of recrystallized grains measured by DCT. (a) The 3D volume of $240 \times 420 \times$ $420 \mu \mathrm{m}^{3}$; (b) a 2D section. The colors in both (a) and (b) represent the crystallographic orientation along RD (see the inset in (a)). In (b) thin and thick black lines represent boundaries with misorientation $>2^{\circ}$ and $>15^{\circ}$, respectively. The voxel/pixel size is $0.77 \mu \mathrm{m}$. 

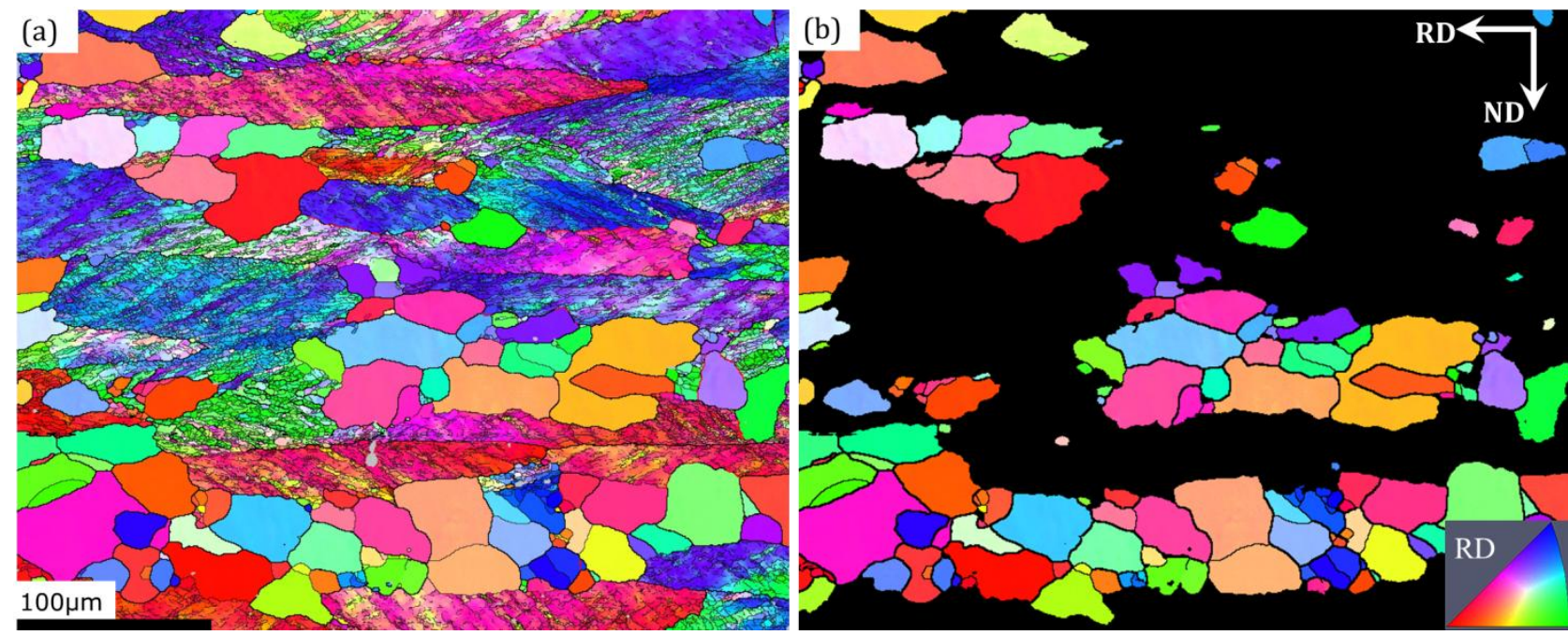

Figure 3. Example of microstructure of the partially recrystallized Al sample: (a) full map, (b) recrystallized grains. The colors used in the EBSD maps correspond to the crystallographic orientations along sample RD (see the inset in (b)). Thin and thick black lines represent boundaries with misorientation $>2^{\circ}$ and $>15^{\circ}$, respectively. The pixel size of the EBSD map is $0.5 \mu \mathrm{m}$. 


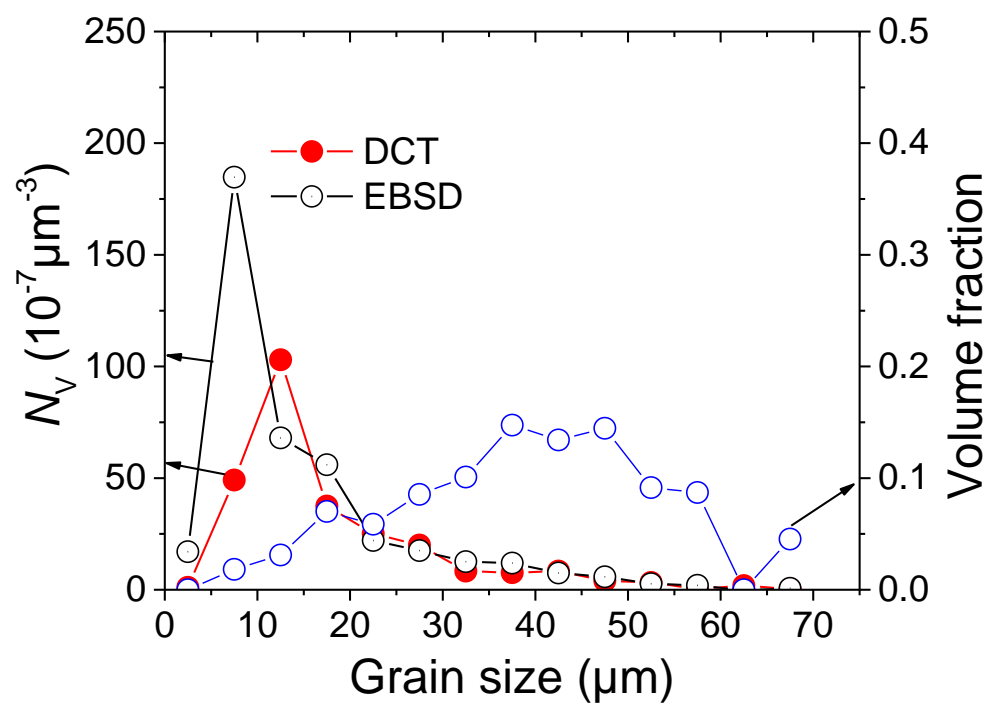

Figure 4. Distributions of grain size $\left(D_{\mathrm{ESD}}\right)$ and volume fraction of recrystallized grains determined based on EBSD and DCT data. The volume fraction is calculated based on the distribution of $N_{\mathrm{V}}$ from the EBSD data using the SS method. 
Supplementary Material
Click here to download Supplementary Material: supplementary materials.pdf

Supplementary Material
Click here to download Supplementary Material: supplementary materials.pdf Click here to download Supplementary Material: supplementary materials.pdf

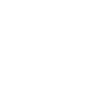

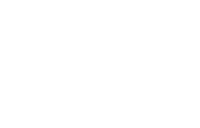

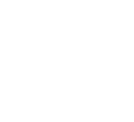

(1)

(1)

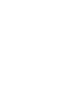

(25)

(1)

(1)

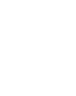

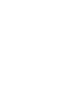

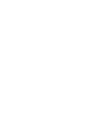

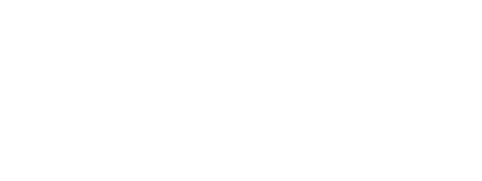

